B IG HE A D

\title{
Geklebte Bolzen für CFK-Bauteile
}

Aston Martin setzt Bolzen des britischen Herstellers Bighead in Bournemouth für Verbindungen von CFK-Automobilteilen ein. Diese Verbindungselemente werden ohne Durchbohrung an der Innenseite der Diffusoren befestigt. Bei der Montage bleiben die Faserstrukturen unversehrt und die Bolzen unsichtbar, teilt der Vertriebspartner KVT Solutioneering Group im schweizerischen Dietikon mit. Diese Entwicklung zum Einbetten, Eingießen, Auf- und Einkleben in Verbundkunststoffe erlaube eine schnelle und materialschonende Produktion.

Ein Merkmal des Bolzens ist der perforierte Kopf, durch den der Klebstoff SW 7271 des Herstellers $3 \mathrm{M}$ fließt. Dadurch hält der Bolzen nach Angaben von KVT sehr hohen
Zug- und Torsionsbelastungen stand. Das sei bei Diffusoren erforderlich, die im Unterbodenbereich eine Sogwirkung erzeugten und so die Aerodynamik des Fahrzeugs verbesserten.

Für Befestigung weicher oder poröser Leichtbauplatten hat Bighead die Blindniet-

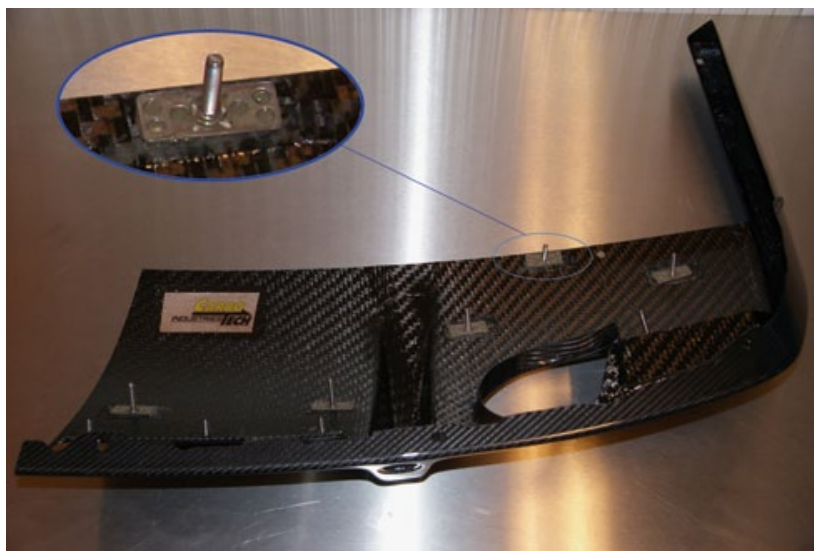
mutter Fasteks+ KDTech im Programm. Unter der Eigenmarke Fasteks wurde das Programm um Blindniete und Blindnietmut- tern erweitert. Für Sandwichpaneelen gibt es das Verbindungselement Twindesk.

\section{Keilsicherungsscheiben für festen Schraubensitz}

Dort, wo Teile in Bewegung sind, sind starke Verbindungen gefragt. Die KB-plus H-Lock Keilsicherungsscheiben von Kuhlmann Befestigungselemente in Bielefeld halten nach Angaben des Unternehmens selbst extremen Vibrationen oder dynamischen Belastungen stand. Grund dafür sei der besondere Aufbau des Scheibensystems, das durch Radialrippen und Keilflächen mehr Klemmkraft aufbringe. Die Keilsicherungsscheiben sind laut Kuhlmann überall dort einsetzbar, wo an Schraubverbindungen hohe Ansprüche gestellt werden. Sie böten perfekte Voraussetzungen zur Verwendung in vielen Bereichen.

Die Sicherungsscheiben aus Stahl mit Zinklamellen-Beschichtung und Edelstahl sind paarweise miteinander verklebt. „Keilflächen auf der Innenseite und Radialrippen auf der Außenseite sorgen für den perfekten Halt, denn beim Anziehen der
Schraube prägen sich die Radialrippen fest in die jeweilige Gegenauflage", heißt es.

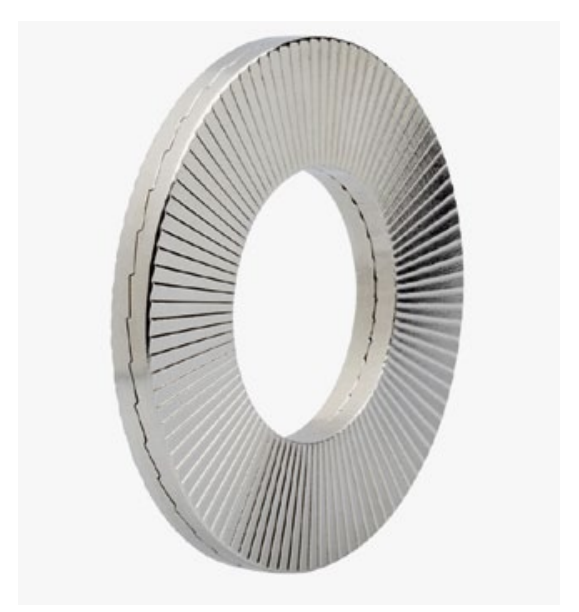

Dadurch gebe es nur noch innerhalb der innenliegenden Keilflächen Bewegungs- möglichkeiten, wodurch höchste Klemmkraft gegeben sei. Kuhlmann ersetzt damit Reibung durch Vorspannkraft und macht Schraubverbindungen mit H-Lock langlebiger und stabiler.

Die ohne Qualitätsverlust wiederverwendbaren Scheiben seien für nahezu alle Schraubentypen geeignet. Das erlaubten auch die Abmessungen $\mathrm{M} 3$ bis M42 sowie $1 / 4$ bis 1 Zoll in schmaler und breiter Ausführung. Das Bielefelder Unternehmen liefert alle Produkte nach festgelegten aktuellen Normen und bietet zusätzlich Sonderanfertigungen, Zeichnungsteile, Systemtechnik oder abnahmepflichtige Verbindungselemente an. Mit H-Lock, der Marke KB-plus, vielen weiteren Produkten und einem flexiblen Kundenservice setzt Kuhlmann nach eigenen Angaben Maßstäbe in Qualität und Fortschritt. 